\title{
Editorial
}

\section{Cell death in the fly comes of age}

\author{
S Kumar, \\ 1 Hanson Centre for Cancer Research, Institute of Medical and Veterinary \\ Science, PO Box 14, Rundle Mall, Adelaide, SA 5000, Australia \\ * Corresponding author: S Kumar; Fax: +61-8-8222-3139; \\ E-mail: sharad.kumar@ imvs.sa.gov.au
}

For almost a century Drosophila melanogaster has been a favourite experimental system for geneticists and developmental biologists, making it one of the most thoroughly studied model organisms in biology. However, the study of cell death pathways in the fly is a relatively recent undertaking. While in the mid 1980s information about apoptotic pathways came from genetic studies in Caenorhabditis elegans ${ }^{1}$ and a little later in mammals with the discovery of the function of $\mathrm{Bcl}-2$ as an apoptosis inhibitor, ${ }^{2}$ the fly only started making headlines in early 1990s. At the time when the cloning of ced-3, the first $C$. elegans death gene, was published in $1993,{ }^{3}$ Drosophila was making its debut as model system to study the molecular basis of cell death, ${ }^{4}$ although sporadic reports of the study of cell death in insect development predated this by a few decades. ${ }^{5,6}$ In 1994 , the results from genetic screens for cell death activators in the fly were published. ${ }^{7}$ Since then, like in the mammalian system, there has been a rapid progress in identifying molecules that make up the apoptotic apparatus in Drosophila. However, despite having all the tools, the understanding of fly death pathways is still relatively nascent, but this may be about to change. With the fly genome now essentially sequenced, ${ }^{8}$ we know most of the components that are predicted to make the fly death machinery, the signalling molecules that are likely to activate the death machinery and the molecules that regulate cell death. Given the importance of the fly model in understanding the regulation of programmed cell death, the editors of this journal felt it necessary to try to collate and integrate most of what we currently know about programmed cell death in the fly. This special issue of Cell Death and Differentiation is the result of such an endeavour.

The first of the articles in this series, authored by Bangs, Franc and White, ${ }^{9}$ reviews the current understanding of the molecular mechanisms that mediate programmed cell death in the fly. The analysis of the Drosophila genome predicts about 50 proteins with a role in cell death pathways. ${ }^{8}$ In addition to several proteins with predicted functions in apoptosis signalling and regulation, these include seven caspases, two Bcl-2 homologues, an Apaf-1 homologue, two IAP homologues, a p53 homologue, a FADD homologue, and functional homologues of $C A D$ and ICAD. $^{8}$ In addition, Drosophila has cell death activators, Rpr, Hid and Grim, for which a putative functional homologue in mammals has recently been described. ${ }^{10,11}$ This protein, named Diablo/Smac, interacts with IAPs and promotes caspase activation. ${ }^{10,11}$ Despite its functional similarity to Rpr, Hid and Grim, this protein does not share any structural similarity with the fly proteins.
One of the essential features of apoptotic cell death is that the cell corpses are rapidly removed by phagocytosis without any leakage of the contents of the dying cell. The mechanism of recognition of apoptotic cells by the engulfing cells, which is just beginning to be understood, involves expression of specific proteins on the surface of both dying and engulfing cells. Although some recent studies have reported the identity of some of these molecules in mammalian systems, ${ }^{12}$ perhaps not surprisingly, Drosophila has also contributed to the understanding of the genetic basis of engulfment. The last section of the article by Bangs et $a l^{9}{ }^{9}$ reviews the present status of what is known about the engulfment of cell corpses in Drosophila.

In mammals, the tumour suppressor protein p53 is a key sensor of DNA damage. In response to genotoxic agents, p53 regulates cell cycle and apoptosis, allowing cells either to repair the damage, or eliminate damaged cells that may otherwise be harmful. ${ }^{13}$ While $C$. elegans lacks a p53 homologue, two groups independently published identification and characterisation of the fly p53 earlier this year. ${ }^{14,15}$ The findings reported on fly p53 are reviewed by Nordstrom and Abrams, ${ }^{16}$ the authors who contributed to the original cloning and characterisation of this protein. One of the most exciting findings from the fly p53 studies is that this protein can directly regulate the transcription of the death activator $r p r$ in the radiation response pathway, thereby directly linking the damage response to the activation of the cell death machinery to eliminate damaged cells via apoptosis. The fly p53, unlike its mammalian counterpart, does not appear to have a function in inhibiting cell cycle progression, suggesting that the cell death function of p53 in response of DNA damage is evolutionarily more ancient than its cell cycle role.

Cysteine proteases of the caspase family are the main effectors of apoptosis in C. elegans and in vertebrates. ${ }^{17}$ The third review in this series summarises the current state of knowledge of these molecules in the fly. ${ }^{18}$ Only a small number of all known caspases in mammals have been shown to play a definitive role in apoptosis. Some others are known to have functions in the inflammatory response pathways by mediating activation of proinflammatory cytokines. ${ }^{17}$ Of the seven Drosophila caspases, five have been characterised so far and all have a predicted role in apoptosis. However, evidence is beginning to appear that suggests that at least one caspase, Dredd, is also a key player in regulating innate immune response, ${ }^{19}$ suggesting that some of the other fly caspases may be involved in processes unrelated to apoptosis. In the mammals, two types of caspases are found. The upstream or initiator caspases, such as caspase-8 and caspase- 9 , contain protein-protein interaction motifs in their amino-terminal prodomains that mediate their interaction with the death signalling complex via specific adaptor molecules, such as 
FADD and Apaf-1. ${ }^{20}$ In Drosophila, the caspases Dronc and Dredd contain protein - protein interaction motifs which mediate their interaction with the Apaf-1 homologue Dark. $^{21-23}$ The downstream or effector caspases, such as caspase- 3 and caspase- 7 in mammals, are activated by initiator caspases. In the fly, Dcp-1, Drice and Decay are likely to be the counterparts of mammalian effector caspases. Thus, the overall complexity of the caspase cascade in the fly is very similar to that in mammals.

In mammals the inappropriate activation/activity of caspases is regulated by several groups of proteins including prosurvival $\mathrm{Bcl}-2$ family members, FLIP and IAPs. ${ }^{24}$ Although Drosophila has two Bcl-2-like proteins, it is as yet unclear whether either of these is a prosurvival protein. ${ }^{25-27}$ There are no fly homologues of FLIP, but Drosophila has four proteins that contain at least one baculovirus IAP repeat (BIR). As discussed in a comprehensive article by $\mathrm{Hay}^{28}$ at least two of these proteins, Diap1 and Diap2, are key regulators of apoptosis in Drosophila. Similar to some of the mammalian IAPs, Diap1 also inhibits apoptosis by directly inhibiting caspases. Mutation analysis suggests that Diap1-mediated caspase inhibition in the fly is essential for cell survival. ${ }^{29,30}$ Since Diap1 also interacts with the death inducers Rpr, Hid and Grim, there is model emerging that suggests that Rpr, Hid and Grim promote apoptosis by inhibiting Diap1 function. ${ }^{29,30}$ This model is supported by the identification of mammalian Diablo/Smac, a protein that seems to promote caspase activation by sequestering IAPs. ${ }^{10,11}$ However, the picture is likely to be even more complex, as the RING domain found in some inhibitory IAPs has been shown to act as a uniquitin-protein ligase. ${ }^{31,32}$ This ligase activity controls the autoubiquitination of some IAPs and has been shown to monoubiquitinate caspase- 3 and caspase-7 in vitro. ${ }^{32}$ Although, the in vivo physiological significance of these findings is currently unclear, ubiquitinmediated turnover of IAPs may play an important regulatory role in apoptosis. ${ }^{31,32}$

In addition to its function in the adult tissue homeostasis, programmed cell death plays a fundamental role in pattern formation and morphogenesis during embryonic and adult animal development. ${ }^{5,6}$ This is one area of apoptosis that is very poorly understood at present and knock-out studies in mouse have not been very informative. With the power of well developed genetics of the fly, Drosophila is expected to make big contributions to the understanding of pathways that mediate developmentally programmed cell death. This is already becoming apparent with the emerging concept that many of the death regulatory genes may be transcriptionally regulated in the cells condemned to die. Three articles cover this temporal and spatial cell death in Drosophila. The article by Baehrecke ${ }^{33}$ discusses the regulation of developmentally programmed cell death by steroid hormones. In Drosophila, a single steroid hormone, ecdysone, controls cell death, survival and differentiation during metamorphosis. ${ }^{34}$ Pulses of ecdysone are produced at various stages of fly development transforming a larva into an adult fly. The most studied systems for ecdysone regulated apoptosis include the nervous system, larval midgut and larval salivary glands. During Drosophila metamorphosis, larval tissues, such as midgut and salivary glands are deleted by apoptosis and replaced by tissues that will be retained in the adult. ${ }^{34}$ The effects of ecdysone are mediated by the levels of ecdysone itself which triggers stage and cell specific responses, by regulating the expression of a number of early and late genes. Ecdysone complexed with its heterodimeric receptor binds to DNA and regulates the transcription of several genes, some of which in turn regulate the transcription of target genes. ${ }^{34}$ The cell death effectors that are currently known to be regulated by ecdysone include Rpr, Grim, Dark and Dronc. $^{33,35}$ These studies are providing important insights into how transcriptional regulation of death genes can control temporal and spatial cell death in complex developmental pathways.

Temporal and spatial control of cell death during development is also fundamental to precise sculpting of tissues. In the next article in this series, Rusconi, Hays and Cagan $^{36}$ review the role of programmed cell death in patterning that occurs during all stages of development to selectively remove cells that have no function or which are no longer required at a given stage of development. The authors provide a comprehensive discussion of cell death and its genetic regulation during segmentation, formation of midline, head development and metamorphosis. They also review programmed cell death that occurs during the patterning of the retina. Although the molecular basis of signalling that removes some cells but spares others is still poorly understood, some common themes are beginning to appear. For example, Notch and EGF signalling seems to be used in different cells at multiple stages, whereas, as also discussed in the article by Baehrecke, ${ }^{33}$ ecdysone regulates death at specific stages during metamorphosis. On the other hand, the death effectors Rpr, Hid and Grim appear to be required for most patterned cell deaths.

Buszczak and Cooley ${ }^{37}$ review cell death during oocyte maturation in Drosophila, with a special focus on the death of nurse cells. In both the fly and mammals, extensive programmed cell death occurs in the female germ line to remove defective cells and to provide nutrients for the surviving oocytes. Drosophila has proven to be a very useful system to understand the genetics basis of female germ cell death and the first discovery of programmed cell death in egg chambers goes back to $1976 .{ }^{38}$ In addition to the egg chambers, the nurse cells that supply nutrients to the developing oocyte also undergo apoptosis after dumping their cytoplasmic contents into the oocyte. This, rather unique system of cell death, is currently only known to exist in nurse cells. An interesting aspect of cell death in the female germline is the apparent lack of involvement of $\mathrm{Rpr}$, Hid and Grim proteins in the mediation of apoptosis. ${ }^{39}$ Although both ecdysone and DPP, a TGF $\beta$ family member, have been implicated in Drosophila germ line apoptosis, at present it is not entirely clear what upstream signals regulate caspase activation during oogenesis.

From the biomedical perspective, one must ultimately ask whether study of fly cell death has been beneficial to the understanding of death pathways in mammals, given that there was already more molecular insight available about cell death pathways in mammals even before the first 
death genes in fly were discovered. The answer to this, at least from a personal perspective, is a resounding yes. For instance, the clearest understanding of IAP function in cell death regulation has come from genetic studies in Drosophila, and this knowledge was crucial to predicting the mechanism of Diablo/Smac function. ${ }^{10,11}$ Studies in Drosophila provided the first in vivo evidence that the inhibition of caspases by p35 can rescue apoptosis on a long term basis, ${ }^{40}$ lending support to the notion that caspase inhibitors may be effective in preventing neurodegeneration, at least in some pathological scenarios. Furthermore, as elegantly discussed by Chan and Bonini, ${ }^{41}$ Drosophila is a powerful system to study human neurodegenerative disorders such as Alzheimer, Parkinson and Huntington diseases. Some of the genes implicated in human diseases, such as APP and presenilins in Alzheimer disease have homologues in the fly, whereas in other cases the expression of human transgenes in the fly has provided useful information on the mechanism of action of some of the mutant proteins in disease pathology. For example, polyglutamine-induced neurodegeneration can be faithfully recapitulated in the fly, and this model has been used to identify suppressors of neurodegeneration, ${ }^{41-43}$ illustrating the power of Drosophila genetics in understanding disease mechanisms and in identifying genes that modify the function of disease genes. Near completion of the Drosophila genomic sequence has resulted in the identification of fly homologues of human disease genes such as SCA2 (the gene mutated in spinocerebeller ataxia type 2) and parkin (involved in juvenile onset parkinsonism). ${ }^{41}$ No doubt, study of these fly genes will provide important information about the human degenerative disorders.

Now armed with the almost complete genomic sequence, along with years of sophisticated genetics behind it, there is no doubt that Drosophila will continue to provide fundamental information about complex biological pathways such as cell death, for many years into the new millennium. With this in mind, I hope that the series of reviews published in this issue of Cell Death and Differentiation will be useful to researchers working with both the invertebrate and vertebrate model systems.

\section{Acknowledgements}

This special issue would not have been possible without the cooperation of the various colleagues who contributed articles to this series, those who participated in the review process (often at a very short notice) and those who made valuable suggestions. I am also grateful to Helena Richardson for stimulating discussions.

\section{References}

1. Ellis HM and Horvitz HR (1986) Genetic control of programmed cell death in the nematode C. elegans. Cell 44: 817-829

2. Vaux DL, Cory S and Adams JM (1988) BCl-2 gene promotes haemopoietic cell survival and cooperates with c-myc to immortalize pre-B cells. Nature 335: 440442
3. Yuan J, Shaham S, Ledoux S, Ellis HM and Horvitz HR (1993) The C. eleganscell death gene ced-3 encodes a protein similar to mammalian interleukin- 1 betaconverting enzyme. Cell 75: 641-652

4. Abrams JM, White K, Fessler LI and Steller H (1993) Programmed cell death during Drosophila embryogenesis. Development 117: 29-43

5. Lockshin RA (1997) The early modern period in cell death. Cell Death Diff. 4: 347-351

6. Vaux DL and Korsmeyer SJ (1999) Cell death in development. Cell 96:245-254

7. White K, Grether ME, Abrams JM, Young L, Farrell Kand Steller H (1994) Genetic control of programmed cell death in Drosophila. Science 264: 677-683

8. Rubin GM, Yandell MD, Wortman JR, Miklos GLG, Nelson CR, Hariharan IK, Fortini ME, Li PW, Apweiler R, Fleischmann W, Cherry JM, Henikoff S, Skupski MP, Misra S, Ashburner M, Birney E, Boguski MS, Brody T, Brokstein P, Celniker SE, Chervitz SA, Coates D, Cravchik A, Gabrielian A, Galle RF, Gelbart WM, George RA, Goldstein LSB, Gong F, Guan P, Harris NL, Hay BA, Hoskins RA, LiJ, Li Z, Hynes RO, Jones SJM, Kuehl PM, Lemaitre B, Littleton JT, Morrison DK, Mungall C, O'Farrell PH, Pickeral OK, Shue C, Vosshall LB, Zhang J, Zhao Q, Zheng XH, Zhong F, Zhong W, Gibbs R, Venter JC, Adams MC and Lewis S (2000) Comparative genomics of the eukaryotes. Science 287: 2204-2215

9. Bangs $P$, Franc $N$ and White $K$ (2000) Molecular mechanisms of cell death and phagocytosis in Drosophila. Cell Death Diff. 7: 1027-1034

10. Du C, Fang M, Li Y, Li L and Wang X (2000) Smac, a mitochondrial protein that promotes cytochrome $c$-dependent caspase activation by eliminating IAP inhibition. Cell 102: 33-42

11. Verhagen AM, Ekert PG, Pakusch M, Silke J, Connolly LM, Reid GE, Moritz RL, Simpson RJ and Vaux DL (2000) Identification of DIABLO, a mammalian protein that promotes apoptosis by binding to and antagonizing IAP proteins. Cell 102: $43-53$

12. Green DR and Beere HM (2000) Apoptosis: Gone but not forgotten. Nature 405: 28-29

13. Lohrum MA and Vousden KH (2000) Regulation and function of the p53-related proteins: same family, different rules. Trends Cell Biol. 10: 197-202

14. Brodsky MH, Nordstrom W, Tsang G, Kwan E, Rubin GM and Abrams JM (2000) Drosophilap53 binds a damage response element at the reaper locus. Cell 101: $103-113$

15. Ollmann M, Young LM, DiComo CJ, KarimF, Belvin M, Robertson S, WhittakerK, Demsky M, Fisher WW, Buchman A, Duyk G, Friedman L, Prives C and KopczynskiC (2000) Drosophilap53 is a structural and functional homolog of the tumor suppressor p53. Cell 101: 91-101

16. Nordstrom W and Abrams JM (2000) Guardian ancestry: Fly p53 and damageinducible apoptosis. Cell Death Diff. 7: 1035-1038

17. Nicholson DW (1999) Caspase structure, proteolytic substrates, and function during apoptotic cell death. Cell Death Diff. 6: 1028-1042

18. Kumar S and Doumanis J (2000) The fly caspases. Cell Death Diff. 7: 10391044

19. Elrod-Erickson M, Misra S and Schneider D (2000) Interaction between the cellular and humoral immune response in Drosophila. Curr. Biol. 10: 781 -784

20. Kumar S (1999) Mechanisms mediating caspase activation in apoptosis. Cell Death Diff. 6: 1060-1066

21. Rodriguez $A$, Oliver $H, Z$ Zou H, Chen $P$, Wang $X$ and Abrams JM (1999) Dark is a Drosophila homologue of Apaf-1/CED-4 and functions in an evolutionarily conserved death pathway. Nat. Cell Biol. 1: 272-279

22. Zhou L, Song Z, Tittel J and Steller H (1999) HAC-1, a Drosophila homolog of APAF-1 and CED-4 functions in developmental and radiation-induced apoptosis. Mol. Cell 4: 745-755

23. Kanuka H, Sawamoto K, Inohara N, Matsuno K, Okano H and Miura M (1999) Control of the cell death pathway by Dapaf-1, a Drosophila Apaf-1/CED-4-related caspase activator. Mol. Cell 4: 757-769

24. Ekert PG, Silke J and Vaux DL (1999) Caspase inhibitors. Cell Death Diff. 6: $1081-1086$

25. Colussi PA, Quinn LM, Huang DCS, Coombe M, Read SH, Richardson H and Kumar S (2000) Debcl, a proapoptotic Bcl-2 homologue, is a component of the Drosophila melanogaster cell death machinery. J. Cell Biol. 148: 703-714

26. Brachmann CB, Jassim OW, Wachsmuth BD and Cagan RL (2000) The Drosophila bcl-2 family member dBorg-1 functions in the apoptotic response to UV-irradiation. Curr Biol. 10:547-550

27. Igaki T, Kanuka H, Inohara N, Sawamoto K, Nunez G, Okano H and Miura M (2000) Drob-1, a Drosophilamember of the Bcl-2/CED-9 family that promotes cell death. Proc. Natl. Acad. Sci. USA 97: 662-667 
28. Hay B (2000) Understanding IAP function and regulation: a view from Drosophila. Cell Death Diff. 7: 1045-1056

29. Wang SL, Hawkins CJ, Yoo SJ, Muller HA and Hay BA (1999) The Drosophila caspase inhibitor DIAP1 is essential for cell survival and is negatively regulated by HID. Cell 98: 453-463

30. Goyal L, MacCall K, Agapite J, Hartwieg E and Steller H (2000) Induction of apoptosis by Drosophila reaper, hid and grim through inhibition of IAP function. EMBO J. 19: 589-597

31. Yang Y, Fang S, Jensen JP, Weissman AM and Ashwell JD (2000) Ubiquitin protein ligase activity of IAPs and their degradation in proteosomes in response to apoptotic stimuli. Science 288: $874-877$

32. Huang H-K, Joazeiro CAP, Bonfoco E, Kamada S, Leverson JD and Hunter T (2000) The inhibitor clAP1, functions as a ubiquitin-protein ligase and promotes in vitro mono-ubiquitination of caspases-3 and -7. J. Biol. Chem. 275: 26661 26664

33. Baehrecke EH (2000) Steroid regulation of programmed cell death during Drosophila development. Cell Death Diff. 7: 1057-1062

34. Jiang C, Baehrecke EH and Thummel CS (1997) Steroid regulated programmed cell death during Drosophila metamorphosis. Development 124: 4673-4683

35. Jiang C, Lambin A-FJ, Steller $\mathrm{H}$ and Thummel CS (2000) A steroid-triggered transcriptional hierarchy controls salivary gland cell death during Drosophila metamorphosis. Mol. Cell 5: 445-455
36. RusconiJC, Hays Rand Cagan RL (2000) Programmed cell death and patterning in Drosophila. Cell Death Diff. 7: 1063-1070

37. Buszczak M and Cooley L (2000) Eggs to die for: Cell death during Drosophila oogenesis. Cell Death Diff. 7: 1071-1074

38. Giorgi F and Deri P (1976) Cell death in ovarian chambers of Drosophila melanogaster. J. Embryol. Exp. Morphol. 35: 521-533

39. Foley Kand Cooley L (1998) Apoptosis in late stage Drosophila nurse cells does not require genes within the H99 deficiency. Development 125: 1075-1082

40. Davidson FF and Steller H (1998) Blocking apoptosis prevents blindness in Drosophila retinal degeneration mutants. Nature 391: 587-591

41. Chan HYE and Bonini NM (2000) Drosophila models of human neurodegenerative disease. Cell Death Diff. 7: 1075-1080

42. WarrickJM, Paulson HL, Gray-Board GL, Bui QT, Fischbeck KH, Pittman RN and Bonini NM (1998) Expanded polyglutamine protein forms nuclear inclusions and causes neural degeneration in Drosophila. Cell 93: 939-949

43. Kazemi-Esfarjani P and Benzer S (2000) Genetic suppression of polyglutamine toxicity in Drosophila. Science 287: 1837-1840 